\title{
Tropical cyclones and climate change: unresolved issues
}

\author{
Kevin Walsh* \\ School of Earth Sciences, University of Melbourne, 3010 Victoria, Australia
}

\begin{abstract}
This paper reviews our current understanding of the effect of climate change on tropical cyclones. While there are presently no discernible changes in tropical cyclone characteristics that could reasonably be ascribed to global warming, predictions suggest some increases in tropical cyclone maximum intensity in a warmer world. Formation regions are unlikely to change, while little consensus has emerged regarding changes in cyclone numbers or tracks. Some uncertainty in these predictions is created by clear deficiencies in current climate models. If predictions of intensities are correct, however, changes should be detectable in the Atlantic some time after 2050.
\end{abstract}

KEY WORDS: Tropical cyclones $\cdot$ Climate change $\cdot$ Global warming

Resale or republication not permitted without written consent of the publisher

\section{INTRODUCTION}

Policy makers often ask tropical cyclone experts whether global warming will affect tropical cyclones. The recent IPCC (Intergovernmental Panel on Climate Change) Third Assessment Report (2001) indicated that some increases in tropical cyclone maximum intensities in a warmer world were 'likely, in some regions'. This is, of course, a fairly broad-brush conclusion and several issues remain unresolved. Given the perceived importance of this topic, it seems timely to review both current knowledge and to suggest new directions for research.

As recently as 7 years ago, essentially nothing was known regarding this topic, despite some speculation. By 1998, Henderson-Sellers et al. (1998) had noted the following:

- There were no discernible trends in tropical cyclone numbers, intensities or locations from historical analyses

- Regional variability was large and would act to obscure such trends

- Both existing empirical methods and numerical models had not demonstrated predictive skill under greenhouse conditions
- Thermodynamic models seemed to have some skill at predicting maximum potential intensities of tropical cyclones, and these models indicated a 10 to $20 \%$ increase in maximum potential intensities under doubled $\mathrm{CO}_{2}$ conditions

- There was no evidence to suggest any major changes in the area or global location of tropical cyclone genesis under greenhouse conditions.

The next major review published was that of Giorgi et al. (2001), incorporated into IPCC (2001). By this time, work published between 1998 and 2001 had strengthened the argument that tropical cyclones might increase in maximum intensity, so that Giorgi et al. (2001) concluded the following:

- There was no evidence for projected changes in the regions currently affected by tropical cyclones

- Changes in numbers could be significant in some regions, mostly tied to possible changes in the behaviour of the El Niño/Southern Oscillation phenomenon (ENSO). A trend seen in a number of general circulation model (GCM) simulations, to a more 'El Niño-like climate' in a warmer world, might lead to tropical cyclone formation that is more similar to that seen in El Niño years than that in the current average climate 
- There was an emerging consensus that maximum tropical cyclone intensities (i.e. wind speeds) were likely to increase by 5 to $10 \%$ in a doubled $\mathrm{CO}_{2}$ climate (i.e. some time after 2050). This would be accompanied by increases in peak precipitation rates of 20 to $30 \%$.

The IPCC (2001) also noted that there was now a 'discernible influence' of human activities on the global climate, with the main evidence being unprecedented high global mean temperatures during the 1990 s, a trend that has continued into the early years of the 21st century (details available at NCDC, http:// www.ncdc.noaa.gov/oa/climate/research/2003/jun/ global.html\#Temp). While the evidence that anthropogenic greenhouse gases are having important effects on the global climate becomes more convincing every year, we remain considerably uncertain of their effect on tropical cyclones. This paper delineates unresolved issues and suggests some approaches that may help reduce this uncertainty.

\section{CURRENT CHANGES IN TROPICAL CYCLONE CHARACTERISTICS}

Currently, there appear to be no detectable changes in observed tropical cyclone characteristics that can be genuinely ascribed to global warming. Nor are there likely to be for several decades: the interannual and decadal variation of tropical cyclone behaviour is large and the likely changes due to global warming will take some time to emerge unambiguously from the observed record.

There are strong interannual relationships between cyclone formation in a number of regions and ENSO. These have been described by many authors (e.g. Hastings 1990, Evans \& Allan 1992, Lander 1994, Basher \& Zheng 1995, Goldenberg \& Shapiro 1996, Chu \& Wang 1997, Chan 2000, Chia \& Ropelewski 2002), so they will not be reiterated here. There are also substantial variations from decade to decade in tropical cyclone numbers in some basins (e.g. Chu \& Clark 1999, Joseph \& Xavier 1999, Elsner \& Kocher 2000, Goldenberg et al. 2001, Grant \& Walsh 2001, Huang \& Yim 2001, Matsuura et al. 2003). Both of these modes of variation make detection of a climate change signal difficult.

As a result, few significant trends have been found. In the Atlantic, Solow \& Moore (2002) showed that there was no trend in north Atlantic hurricane activity from 1900 to 1998. Nicholls et al. (1998) indicated that there has been a downward trend in tropical cyclone numbers in the Australian region since the late 1960s, but this has been caused by changes in analysis procedures and by more El Niños occurring in this region in the latter part of the record. In the northwest Pacific, Chan \& Shi (1996) showed that while there was a downward trend in numbers from 1959 to the late 1980s, there has been an upward trend since then. For other basins, since the 1960s the northeast Pacific has experienced an upward trend, the north Indian a downward trend (Raghavan \& Rajesh 2003) and no trends have been seen in the southwest Indian and southwest Pacific (Henderson-Sellers et al. 1998).

A recent development has been in the field of palaeotempestology, or the analysis of palaeoclimate evidence of past tropical cyclones (Liu \& Fearn 1993, 2000, Donnelly et al. 2001a,b). Usually, this evidence takes the form of debris fields or overwash deposits in the geologic record, found in specific locations. These deposits are then interpreted, sometimes with the aid of numerical models, as being caused by cyclones of varying intensities. The main motivation behind this work is to extend the tropical cyclone record to longer periods than the observed record, which is usually too short to establish reliable return periods for intense cyclone events. Studies that have been done suggest substantial variations in the incidence of tropical cyclones over periods of centuries and millennia.

In Australia, Nott \& Hayne (2001) mapped the occurrence of coral ridges at locations in the northeast of the country. Associating these ridges with past tropical cyclones, they used the numerical tropical cyclone storm surge model of Hubbert \& McInnes (1999) to assign intensities to these tropical cyclones. They found that the implied past incidence of tropical cyclones with central pressures less than $920 \mathrm{hPa}$ was about a factor of 10 greater than that derived from the historical record. Whether this result will remain robust under future analysis remains to be seen, but it does indicate the potential of this work to establish better the actual incidence of intense tropical cyclones (see also Nott 2003). An important aspect to consider in evaluating this work is our currently inadequate understanding of many of the relevant processes in coastal geomorphology (e.g. Woodroffe 2002). Mechanisms for these long variations are presently unknown, but natural variations on timescales of a century or so may also act to obscure the impact of global warming on tropical cyclones.

\section{POTENTIAL EFFECTS OF CLIMATE CHANGE}

\subsection{Increase in intensity of tropical cyclones}

The IPCC (2001) conclusion of tropical cyclone intensity increase was essentially based upon the results of theoretical techniques that estimate the maximum potential intensity (MPI) of tropical cyclones 
from average climate conditions (Emanuel 1988, Holland 1997, Tonkin et al. 2000) and a few modelling studies (Knutson \& Tuleya 1999, Walsh \& Ryan 2000, Knutson et al. 2001). The theoretical techniques imply a strong relationship between MPI and sea surface temperatures (SST). Real tropical cyclones do not reach their MPI, as factors that act to diminish cyclone intensity, such as vertical wind shear, limit the intensity reached. Recently it has been suggested that ocean heat content, defined as the integrated excess of temperature over $26^{\circ} \mathrm{C}$ down to the $26^{\circ} \mathrm{C}$ isotherm (Leipper \& Volgenau 1972), is more closely related to tropical cyclone intensity than is SST (e.g. Mainelli et al. 2002). It may be useful to re-examine theoretical estimates of MPI using climatological heat content as a lower boundary condition rather than SST. Recently, Bister \& Emanuel (2002) evaluated trends in MPI and found an increase in MPI in the 1990s.

The results of these theoretical predictions are consistent with the modelling studies, but models have used horizontal grid spacings no finer than $18 \mathrm{~km}$ (Knutson \& Tuleya 1999). This is still coarse relative to the actual processes occurring within tropical cyclones. It has been argued that a horizontal resolution of finer than $5 \mathrm{~km}$ (or maybe even down to $1 \mathrm{~km}$ ) would be most suitable for simulating tropical cyclone intensities. Certainly in the climate modelling studies to date the simulation of current climate tropical cyclone intensities could be improved. Walsh et al. (2004) used a resolution of $30 \mathrm{~km}$ and found in their model that, while the distribution of central pressures of the simulated storms was reasonable compared with observations, the pressure gradient close to the centres was inadequately simulated, thus giving weaker than observed wind speeds. The confidence in predictions of higher tropical cyclone wind speeds in a warmer world would be increased by a more skilful simulation of wind speeds in the current climate, which can in principle come from finer horizontal resolution and better model physics. If grid resolutions of $5 \mathrm{~km}$ or less are to be used, then either explicit microphysics should be employed or the convective parameterization would have to address the issue of how to parameterize at a resolution where processes begin to be explicitly resolved. Confidence in these predictions would be increased even further if the same (or a similar) version of a climate model were used to make truly skilful weather forecasts of intensity changes of observed tropical cyclones over periods of 1 or $2 \mathrm{~d}$. While this goal has recently been achieved using statistical models (DeMaria \& Kaplan 1999), dynamical forecast models are yet to do so.

For average tropical cyclone intensities (as opposed to maximum intensities), Emanuel (2000) suggests that the linear nature of the cumulative distribution func- tion of lifetime maximum intensities implies that an increase in the maximum storm intensity would also increase the average intensity. Another point to note is that increases in tropical cyclone intensities are likely to be accompanied by substantial increases in peak rainfall rates. Both Knutson \& Tuleya (1999) and analysis of the results of Walsh \& Ryan (2000) suggest increases in peak precipitation rates of about $25 \%$ in a warmer world (around 2050 or so).

\subsection{Formation of tropical cyclones}

Numerous recent studies have addressed the question of whether tropical cyclone numbers would increase in a warmer world. These have used regional climate models (Walsh \& Katzfey 2000, Nguyen \& Walsh 2001), GCMs (Broccoli \& Manabe 1990, Haarsma et al. 1993, Bengtsson et al. 1996, Krishnamurti et al. 1998, Druyan et al. 1999, Yoshimura et al. 1999, Tsutsui 2002, Sugi et al. 2002) and theoretical techniques (Royer et al. 1998). Little consensus has emerged from these disparate methods. Sugi et al. (2002) used a relatively high-resolution GCM (T106, about equivalent to a horizontal resolution of $100 \mathrm{~km}$ ) to simulate a significant reduction of cyclone numbers in a warmer world, but with large regional differences in model response (increases in the north Atlantic and decreases in the north Pacific). They suggested that these changes were predominantly associated with dynamical rather than thermodynamic mechanisms. In contrast, Walsh \& Katzfey (2000), Tsutsui (2002) and Walsh et al. (2004) found little change in tropical cyclone numbers in a warmer world, although in the GCM study of Tsutsui (2002) there was considerable regional variation in the response.

One difficulty with all of these simulations is that they do not have a simulation of climatologically observed tropical cyclone formation that could be considered genuinely close to reality. In the GCM studies there are large errors in the simulation of current climate formation in some basins. Thus, there is considerable room for improvement.

A large number of different schemes are used to detect tropical cyclone-like vortices (TCLVs) in GCMs. These rely upon combinations of threshold values of detection criteria that are based on the observed structural characteristics of actual tropical cyclones. For instance, a criterion that excludes systems whose wind speeds at $200 \mathrm{hPa}$ are greater than those at $850 \mathrm{hPa}$ will effectively exclude almost all mid-latitude systems. A detection threshold for surface or $10 \mathrm{~m}$ wind speed is also employed; for relatively coarse-resolution GCMs, the chosen threshold is usually lower than the observed tropical cyclone wind speed threshold of 
$17 \mathrm{~ms}^{-1}$. Another approach was employed by Camargo \& Zebiak (2002), who constructed probability distribution functions of tropical cyclone characteristics and assumed that the extreme portion of these distributions represented tropical cyclones.

Of course, it is somewhat ad hoc to use a different threshold wind speed criterion for detection from that actually used to defined observed tropical cyclones (namely $17 \mathrm{~ms}^{-1}$ ). For models with a resolution that is coarse compared with the size of real tropical cyclones, however, it is appropriate to use such a lower threshold, as we know a priori that the model, because of its low resolution, cannot be expected to simulate lows of the same intensity as observed. Nevertheless, there appears to be no genuinely objective means in the literature of determining a threshold wind speed for TCLVs that is appropriate for the resolution of a particular GCM. In theory, one could establish such a threshold using particularly accurate reanalyses averaged to the resolution of the GCM, and then determining what wind speed threshold would detect observed tropical cyclones in the reanalyses while maximizing the probability of detection and minimizing the false alarm rate. In practice, current reanalyses probably do not have a representation of actual tropical cyclone structure that is good enough to do this (Fiorino 2002). Improvements in reanalyses are ongoing, however.

Walsh et al. (2004) concluded that a way to sidestep this issue was simply to run a regional climate model over the region of interest at a high enough resolution so that it generated a good climatology of tropical cyclogenesis using the observed tropical storm wind speed threshold of $17 \mathrm{~ms}^{-1}$. This is naturally more difficult than running a GCM in stand-alone mode, however. In addition, Walsh et al. (2004) note that the resolution of their model (30 km grid spacing) is probably still too coarse to use the observed threshold with confidence. It would also be useful to investigate modifications of existing tropical cyclone genesis parameters (Royer et al. 1998, DeMaria et al. 2001) so that they can be used as a diagnostic tool in climate change simulations.

As stated above, there is considerable scope for improving the GCM simulations of climatological tropical cyclone formation. In addition, there still is no real consensus on the effect of climate change on ENSO, either in terms of possible changes in the time-mean state of the Pacific or changes in the timing and frequency of ENSO oscillations about the mean (IPCC 2001, Hoerling \& Kumar 2003). Since the formation of tropical cyclones in some basins strongly depends on the phase of ENSO, knowledge of any changes in ENSO in a warmer world is important for predicting regional changes in tropical cyclone formation.
Despite this, a number of studies have assessed the ability of models to simulate the observed interannual variability of tropical cyclone numbers. Vitart et al. (1999) and Vitart \& Anderson (2001) used a GCM forced with a version of observed SSTs to obtain quite good simulations of interannual variation of tropical cyclone numbers; again, though, they made certain assumptions about what constituted an appropriate detection threshold. Nguyen \& Walsh (2001) and Walsh \& Syktus (2003) used a regional climate model to perform similar studies.

In contrast to the general issue of numbers of tropical cyclones in a warmer world, there does appear to be some consensus on the issue of whether tropical cyclones would form in regions far outside their current formation basins. There is little theoretical or modelling evidence for changes in formation regions, unless they are associated with possible large-scale changes in ENSO. One reason appears to be a rise of the threshold SST required to initiate deep convection in a warmer world (Dutton et al. 2000), thus leading to no geographical expansion of the area undergoing deep convection.

\subsection{Tracks of tropical cyclones}

Little work has been done on estimating changes in tropical cyclone tracks in a warmer world. Note that this is a different issue from changes in regions of formation: here we are describing changes in tropical cyclone characteristics once the cyclones move out of their tropical regions of formation and travel further poleward. This includes any possible changes in the characteristics of storms undergoing extratropical transition, including the typical intensities of such storms.

Studies that have addressed this issue include Knutson \& Tuleya (1999), who simulated little change in mean tracks in the northwest Pacific under enhanced greenhouse conditions, although their $5 \mathrm{~d}$ simulations did not necessarily encompass the entire tropical cyclone lifecycle. Walsh \& Katzfey (2000) simulated some poleward extension of tracks in a warmer world in the eastern Australian region; however, using a similar modelling system, Walsh et al. (2004) found no substantial impact of enhanced greenhouse conditions on the poleward movement of tropical cyclones in the Australian region. Results from Tsutsui (2002) also suggest little systematic change in tracks. Data analysis and theoretical techniques may play a subsequent role in this issue, as little work has been performed on this topic using either technique. One possible area for investigation is whether warmer SSTs will lead to more energetic extratropical transition of tropical cyclones in some regions of the globe. 


\subsection{Potential impacts}

The most damaging aspect of tropical cyclones in the current climate is storm surge, so it is likely that it will remain so in a warmer world. Storm surge incidence at a location is commonly expressed in terms of the return period of a surge event greater than a specified height above normal sea level. McInnes et al. (2003) made an estimate of the impact of climate change on storm surge return periods in Cairns, Australia. They assumed a decrease in mean tropical cyclone central pressures of $10 \mathrm{hPa}$ and an increase in the standard deviation of $5 \mathrm{hPa}$, based on simulations by Walsh \& Ryan (2000). It was noted that these values might provide an upper limit of intensity change, and so another set of experiments was run assuming no intensity changes for storms with central pressures weaker than $985 \mathrm{hPa}$ and reducing central pressures less than this value by $10 \mathrm{hPa}$. In addition, a projected mean sea level rise of $20 \mathrm{~cm}$ was applied (IPCC 2001). These conditions were assumed to be projections for the period around 2050. The results showed a substantial decrease in the return period of storm surges in Cairns (i.e. more frequent events).

It is debatable whether the results of such studies are yet of high enough reliability to be used for practical planning purposes. For the Cairns region, a source of uncertainty is that cyclone incidence is substantially affected by the phase of ENSO, meaning that a significant change in ENSO behaviour in a warmer world would also change tropical cyclone incidence. Nevertheless, McInnes et al. (2003) calculated that for the projected increase in storm surge incidence to be entirely negated, climatological tropical cyclone numbers in the Cairns region would have to fall by a factor of 3 , which seems like a large change.

Other possible impacts include shorter return periods for strong wind speeds, perhaps ultimately leading to some changes in building design standards in some regions affected by tropical cyclones (Camilleri et al. 2001, Walsh et al. 2001 ). Projected increases in maximum rainfall amounts from tropical cyclones may have implications for the design of infrastructure such as dams and drainage systems, as well as for the incidence of floods.

Whether these impacts are noticeable or not depends considerably on whether the changes caused by climate change are large compared with the present natural interannual or decadal variability. To establish the persistence and periodicity of decadal variability, the length of the reliable data record for tropical cyclones is short. Thus, decadal variability of tropical cyclones is best known in the Atlantic basin, where the reliable observed record is longest (Goldenberg et al. 2001). One could make an approximate esti- mate of the relative sizes of the effects of climate change and decadal variability on tropical cyclones in the following manner. Clark (1997) indicates that an increase in tropical cyclone intensity of 5 to $10 \%$ would cause damage by selected historical tropical cyclones to increase by 35 to $75 \%$, due to the highly non-linear relationship between wind speed and storm damage. We assume that global warming will cause all intense storms to strengthen by the same percentage and that there will be no changes in cyclone numbers. The observed decadal variability in intense tropical cyclone numbers in the Atlantic in the 20th century results in roughly a doubling of average frequency between quiescent periods (1970 to 1987) and active periods (1948 to 1964,1995 to 2002; Goldenberg et al. 2001). Thus, by 2050 this variability will probably still be larger than the effect of global warming, ie. $100 \%$ versus 35 to $75 \%$, although 35 to $75 \%$ still represents a substantial increase in damage. Even so, the global warming contribution to cyclone damage in the Atlantic may become noticeable by this time, since purely demographic effects can be removed as confounding factors (Pielke \& Landsea 1998). After 2050, if the climate continues to warm, as seems likely, the global warming signal will become increasingly dominant.

\section{CONCLUSIONS}

- There is as yet no convincing evidence in the observed record of changes in tropical cyclone behaviour that can be ascribed to global warming

- There is likely to be some increase in maximum tropical cyclone intensities in a warmer world. A range of estimates is given but 5 to $10 \%$ by around 2050 seems reasonable. It is probable that this would be accompanied by increases in mean tropical cyclone intensities. These increases in intensities are likely to be accompanied by increases in peak precipitation rates of about $25 \%$

- There is likely to be no significant change in regions of formation

- There may be substantial regional changes in formation rates, but in a number of basins these are strongly influenced by ENSO, the behaviour of which remains substantially uncertain in a warmer world. Model projections give little consensus on changes in formation rates

- There is little evidence yet of substantial changes in a warmer world in the typical poleward extent of active tropical cyclones, once they leave their tropical regions of formation

- Palaeoclimate indicators suggest substantial variations in the incidence of intense tropical cyclones in 
- some regions, over periods of centuries to millennia; mechanisms for these are presently unclear, but such variations may present an additional confounding factor for any global warming signal

- Provided that no centennial variations in tropical cyclone numbers occur, the climate change signal may be detectable in the Atlantic above the present decadal variability by some time after 2050 .

It is suggested that improvements in our understanding of the effects of climate change on tropical cyclones may come from several approaches:

- Finer horizontal resolution of regional climate models (at least $5 \mathrm{~km}$ ) to accurately simulate the intensities of tropical cyclones, as well as improvements to cloud physics

- Improvement of coupled atmosphere-ocean processes, especially transfer coefficients, which are poorly known for high wind speeds

- Improvements in the simulation of the climatology and variability of vertical wind shear in GCMs, and of the ability of models to simulate the effects of vertical wind shear on genesis and intensification

- Improvements in the representation of tropical cyclone structure in reanalyses to provide a benchmark comparison for numerical simulations

- Testing and improvement of tropical cyclone genesis parameters to give more confidence in their use as a diagnostic tool in climate change studies

- Further evaluation of the ability of models of various resolutions to simulate tropical cyclogenesis, including interannual and decadal variability

- Data analysis and theoretical studies of the influence of enhanced greenhouse conditions on the intensities and tracks of tropical storms in the mid-latitudes.

Acknowledgements. The author would like to thank CSIRO Atmospheric Research, the Department of Natural Resources and Mines of the State Government of Queensland and the University of Melbourne for supporting this work. This is an expanded version of a paper presented at the 14th Annual Bureau of Meteorology Research Centre Modelling Workshop, Melbourne, Nov 11-13, 2002.

\section{LITERATURE CITED}

Basher RE, Zheng X (1995) Tropical cyclones in the southwest Pacific: spatial patterns and relationships to Southern Oscillation and sea surface temperature. J Clim 8:1249-1260

Bengtsson L, Botzet M, Esch M (1996) Will greenhouse gas induced warming over the next 50 years lead to higher frequency and greater intensity of hurricanes? Tellus 48A:57-73

Bister M, Emanuel KA (2002) Low frequency variability of tropical cyclone potential intensity. 1. Interannual to interdecadal variability. J Geophys Res 107: ACL 26 1-15

Broccoli AJ, Manabe S (1990) Can existing climate models be used to study anthropogenic changes in tropical cyclone climate? Geophys Res Lett 17:1917-1920
Camargo SJ, Zebiak SE (2002) Improving the detection and tracking of tropical cyclones in atmospheric general circulation models. Technical Report No. 02-02. International Research Institute for Climate Prediction, Palisades, NY

Camilleri M, Jaques R, Isaacs $N$ (2001) Impacts of climate change on building performance in New Zealand. Building Res Inf 29:440-450

Chan JCL (2000) Tropical cyclone activity over the western North Pacific associated with El Niño and La Niña events. J Clim 13:2960-2972

Chan JCL, Shi JE (1996) Long-term trends and interannual variability in tropical cyclone activity over the western North Pacific. Geophys Res Lett 23:2765-2768

Chia HH, Ropelewski CF (2002) The interannual variability in the genesis location of tropical cyclones in the northwest Pacific. J Clim 15:2934-2944

Chu PS, Clark JD (1999) Decadal variations of tropical cyclone activity over the central north Pacific. Bull Am Meteorol Soc 80:1875-1881

Chu PS, Wang J (1997) Tropical cyclone occurrences in the vicinity of Hawaii: are the differences between El Niño and non-El Niño years significant? J Clim 10:2683-2689

Clark KM (1997) Current and potential impact of hurricane variability on the insurance industry. In: Diaz HF, Pulwarty RS (eds) Hurricanes: climate and socioeconomic impacts. Springer, Berlin, Heidelberg, New York, p 273-284

DeMaria M, Kaplan J (1999) An updated statistical hurricane intensity prediction scheme (SHIPS) for the Atlantic and Eastern North Pacific basins. Wea Forecasting 14:326-337

DeMaria M, Knaff JA, Connell BH (2001) A tropical cyclone genesis parameter for the tropical Atlantic. Wea Forecasting 16:219-233

Donnelly JP, Roll S, Wengren M, Butler J, Lederer R, Webb T (2001a) Sedimentary evidence of intense hurricane strikes from New Jersey. Geology 29:615-618

Donnelly JP, Bryant SS, Butler J, Dowling J and 7 others (2001b) $700 \mathrm{yr}$ sedimentary record of intense hurricane landfalls in southern New England. Geol Soc Am Bull 113: 714-727

Druyan LM, Lonergan P, Eichler T (1999) A GCM investigation of global warming impacts relevant to tropical cyclone genesis. Int J Climatol 19:607-617

Dutton JF, Poulsen CJ, Evans JL (2000) The effect of global climate change on the regions of tropical convection in CSM1. Geophys Res Lett 27:3049-3052

Elsner JB, Kocher B (2000) Global tropical cyclone activity: a link to the North Atlantic Oscillation. Geophys Res Lett 27: 129-132

Emanuel KA (1988) The maximum intensity of hurricanes. J Atmos Sci 45:1143-1155

Emanuel K (2000) A statistical analysis of tropical cyclone intensity. Mon Wea Rev 128:1139-1152

Evans JL, Allan RJ (1992) El Niño/Southern Oscillation modification to the structure of the monsoon and tropical cyclone activity in the Australasian region. Int J Climatol 12:611-623

Fiorino M (2002) Analysis and forecasts of tropical cyclones in the ECMWF 40-year reanalysis (ERA-40). Proc 25th Conf Hurricanes and Tropical Meteorol, San Diego, Apr 29-May 3, 2002. American Meteorological Society, Boston, p 261-264

Giorgi F, Hewitson B, Christensen J, Hulme M and 5 others (2001) Regional climate change information - evaluation and projections. In: Houghton JT, Ding Y, Griggs DJ, Noguer M, van der Linden PJ, Xiaosu D (eds) Climate change 2001 - the scientific basis. Cambridge University Press, Cambridge and New York, p 583-638

Goldenberg, SB, Shapiro LJ (1996) Physical mechanisms for 
the association of El Niño and West African rainfall with Atlantic major hurricane activity. J Clim 9:1169-1187

Goldenberg SB, Landsea CW, Mestas-Nuñez AM, Gray WM (2001) The recent increase in Atlantic hurricane activity: causes and implications. Science 293:474-478

Grant AP, Walsh KJE (2001) Interdecadal variability in northeast Australian tropical cyclone formation. Atmos Sci Lett $2: 9-17$

Haarsma RJ, Mitchell JFB, Senior CA (1993) Tropical disturbances in a GCM. Clim Dyn 8:247-527

Hastings PA (1990) Southern Oscillation influences on tropical cyclone activity in the Australian/south-west Pacific region. Int J Climatol 10:291-298

Henderson-Sellers A, Zhang H, Berz G, Emanuel K and 7 others (1998) Tropical cyclones and global climate change: a post-IPCC assessment. Bull Am Meteorol Soc 79:19-38

Hoerling M, Kumar A (2003) The perfect ocean for drought. Science 299:691-694

Holland GJ (1997) The maximum potential intensity of tropical cyclones. J Atmos Sci 54:2519-2525

Huang G, Yim W WS (2001) An 8000-year record of typhoons in the northern South China Sea. PAGES News 9(2):7-8

Hubbert GD, McInnes KL (1999) A storm surge inundation model for coastal planning and impact studies. J Coast Res 15:168-185

IPCC (Intergovernmental Panel on Climate Change) Houghton JT, Ding Y, Griggs DJ, Noguer M, van der Linden PJ, Xiaosu, D (eds) (2001) Climate change 2001: the scientific basis. Contribution of Working Group I to the Third Assessment Report of the Intergovernmental Panel on Climate Change (IPCC). Cambridge University Press, Cambridge and New York

Joseph PV, Xavier PK (1999) Monsoon rainfall and frequencies of monsoon depressions and tropical cyclones of recent 100 years and an outlook for the first decades of the 21st century. Proc TROPMET-99, Chennai, Feb 16-19, 1999. Indian Meteorological Society, New Dehli, 364-371

Knutson TR, Tuleya RE (1999) Increased hurricane intensities with $\mathrm{CO}_{2}$-induced warming as simulated using the GFDL hurricane prediction system. Clim Dyn 15:503-519

Knutson TR, Tuleya RE, Shen W, Ginis I (2001) Impact of $\mathrm{CO}_{2}$ induced warming on hurricane intensities as simulated in a hurricane model with ocean coupling. J Clim 14: $2458-2468$

Krishnamurti TN, Correa-Torres R, Latif M, Daughenbaugh G (1998) The impact of current and possibly future sea surface temperature anomalies on the frequency of Atlantic hurricanes. Tellus 50A: 186-210

Lander MA (1994) An exploratory analysis of the relationship between tropical storm formation in the western north Pacific and ENSO. Mon Wea Rev 122:636-651

Leipper DF, Volgenau D (1972) Hurricane heat potential of the Gulf of Mexico. J Phys Oceanogr 2:218-224

Liu KB, Fearn ML (1993) Lake sediment record of late Holocene hurricane activities from coastal Alabama. Geology 21:793-796

Liu KB, Fearn ML (2000) Reconstruction of prehistoric landfall frequencies of catastrophic hurricanes in northwestern Florida from lake sediment records. Quat Res 54:238-245

Mainelli M, DeMaria M, Shay LK (2002) The impact of oceanic heat content on hurricane intensity forecasts using the SHIPS model. Proc 25th Conf Hurricanes and Tropical Meteorol, San Diego, April 29-May 3, 2002, American Meteorological Society, Boston, p 627-628

Matsuura T, Yumoto M, Iizuka S (2003) A mechanism of interdecadal variability of tropical cyclone activity over the western North Pacific. Clim Dyn 21:105-117
McInnes KL, Walsh KJE, Hubbert GD, Beer T (2003) Impact of sea-level rise and storm surges on a coastal community. Natural Hazards 30:187-207

Nguyen KC, Walsh KJE (2001) Interannual, decadal and transient greenhouse simulations of tropical cyclone-like vortices in a regional climate model of the South Pacific. J Clim 14:3043-3054

Nicholls N, Landsea C, Gill J (1998) Recent trends in Australian region tropical cyclone activity. Meteorol Atmos Phys 65:197-205

Nott JF (2003) Intensity of prehistoric tropical cyclones. J Geophys Res 108 (D7), 10.1029/2002JD002726 (Abstract)

Nott J, Hayne M (2001) High frequency of 'super-cyclones' along the Great Barrier Reef over the past 5,000 years. Nature 413:508-512

Pielke RA, Landsea CW (1998) Normalized hurricane damages in the United States: 1925-95. Wea Forecasting 13:621-631

Raghavan S, Rajesh S (2003) Trends in tropical cyclone impact: a study in Andhra Pradesh, India. Bull Am Meteorol Soc 84:635-644

Royer JF, Chauvin F, Timbal B, Araspin P, Grimal D (1998) A GCM study of the impact of greenhouse gas increase on the frequency of occurrence of tropical cyclones. Clim Change 38:307-343

Solow AR, Moore LJ (2002) Testing for trend in North Atlantic hurricane activity, 1900-98. J Clim 15:3111-3114

Sugi M, Noda A, Sato N (2002) Influence of the global warming on tropical cyclone climatology: an experiment with the JMA global model. J Meteorol Soc Jpn 80:249-272

Tonkin H, Holland GJ, Holbrook N, Henderson-Sellers A (2000) An evaluation of thermodynamic estimates of climatological maximum potential tropical cyclone intensity. Mon Wea Rev 128:746-762

Tsutsui J (2002) Implications of anthropogenic climate change for tropical cyclone activity: a case study with the NCAR CCM2. J Meteorol Soc Jpn 80:45-65

Vitart F, Anderson JL (2001) Sensitivity of Atlantic tropical storm frequency to ENSO and interdecadal variability of SSTs in an ensemble of AGCM integrations. J Clim 14:533-545

Vitart F, Anderson JL, Stern WF (1999) Impact of large-scale circulation on tropical storm frequency, intensity and location simulated by an ensemble of GCM integrations. J Clim 12:3237-3254

Walsh KJE, Katzfey JJ (2000) The impact of climate change on the poleward movement of tropical cyclone-like vortices in a regional climate model. J Clim 13:1116-1132

Walsh KJE, Ryan BF (2000) Tropical cyclone intensity increase near Australia as a result of climate change. J Clim 13:3029-3036

Walsh KJE, Syktus J (2003) Simulations of observed interannual variability of tropical cyclone formation east of Australia. Atmos Sci Lett 4:28-40

Walsh K, Hennessy K, Jones R, McInnes K, Page C, Pittock AB, Suppiah R, Whetton P (2001) Climate change in Queensland under enhanced greenhouse conditions: Third Annual Report. CSIRO Atmospheric Research, Aspendale

Walsh KJE, Nguyen KC, McGregor JL (2004) Fine-resolution regional climate model simulations of the impact of climate change on tropical cyclones near Australia. Clim Dyn 22:47-56

Woodroffe CD (2002) Coasts: form, process and evolution. Cambridge University Press, Cambridge

Yoshimura J, Sugi M, Noda A (1999) Influence of greenhouse warming on tropical cyclone frequency simulated by a high-resolution AGCM. Proc 23rd Conf Hurricanes and Tropical Meteorol, Jan 10-15, 1999, Dallas. American Meteorological Society, Boston, p 1081-1084 